\title{
Neonatal Seizures
}

\author{
Faye S. Silverstein, MD, ${ }^{1}$ and Frances E. Jensen, $\mathrm{MD}^{2}$
}

In childhood, the risk for seizures is greatest in the neonatal period. Currently used therapies have limited efficacy. Although the treatment of neonatal seizures has not significantly changed in the past several decades, there has been substantial progress in understanding developmental mechanisms that influence seizure generation and responsiveness to anticonvulsants. This review includes an overview of current approaches to the diagnosis and treatment of neonatal seizures, identifies some of the critical factors that have limited progress, and highlights recent insights about the pathophysiology of neonatal seizures that may provide the foundation for better treatment.

Ann Neurol 2007;62:112-120

In childhood, the risk for seizures is greatest in the neonatal period $(1.8-3.5 / 1,000$ live births in the United States). Available data indicate that phenobarbital remains the first-line therapy for treatment of neonatal seizures. ${ }^{1}$ Yet, a recent Cochrane Review concluded that "there is little evidence...to support the use of any of the anticonvulsants currently used in the neonatal period." 2

Although there has been little recent progress in the effective treatment of neonatal seizures, ${ }^{3,4}$ there have been substantial advances regarding understanding pathophysiology and, in particular, developmental stage-specific factors that influence mechanisms of seizure generation, responsiveness to anticonvulsants, and the impact on central nervous system integrity.

Many factors are responsible for the lack of progress in neonatal seizure therapeutics. Rigorous studies have confirmed clinical impressions that the older anticonvulsants have only limited efficacy in neonates (discussed later). To date, no novel compounds have been developed specifically for treatment of neonatal seizures. Other challenges inherent in improving the treatment and outcome of neonatal seizures include the diverse causative factors and comorbidities, and the complexities of seizure diagnosis. Neonates display behaviors that mimic seizures, and electrographic seizures with no clear-cut clinical manifestations ("electroclinical dissociation") are common in neonates. There is consensus that some type of electrophysiological monitoring is essential to confirm the diagnosis of seizures and assess the efficacy of treatment in neonates. It is currently uncertain whether available cortical function monitors (amplitudeintegrated electroencephalographic [EEG] devices) and simplified EEG systems are adequate for seizure detection, and this is an area of active research.

Moreover, experimental data have raised concerns about the potential adverse effects on brain development of currently used (and only modestly effective) anticonvulsants in neonates. The availability of new therapeutic agents has generated substantial optimism that safer and more effective treatment of neonatal seizures is feasible.

In this review, we highlight both areas in which substantial progress has been made, and identify the most important unanswered questions about the pathophysiology and treatment of seizures in neonates. We recommend consultation of reference texts for details regarding differential diagnosis, currently recommended diagnostic evaluation, and treatment of neonatal seizures. $^{5,6}$

\section{Clinical Overview}

Several features distinguish seizures in neonates from those in older children. Neonatal seizures are often behaviorally subtle, and the EEG pattern often reflects a multifocal process, rather than coordinated seizure activity. In addition, diagnosis is complicated by the fact that neonates may display stereotyped repetitive rhythmic movements that would not be conventionally classified as seizures because they lack an EEG correlate. Whether such episodes, which are most commonly observed in encephalopathic infants, represent subcorti-
From the ${ }^{1}$ Departments of Pediatrics and Neurology, University of Michigan, Ann Arbor, MI; and ${ }^{2}$ Department of Neurology, Children's Hospital Boston, Harvard Medical School, Boston, MA.

Received Apr 11, 2007, and in revised form May 22. Accepted for publication May 29, 2007.

Published online August 7, 2007 in Wiley InterScience (www.interscience.wiley.com). DOI: 10.1002/ana.21167
Address correspondence to either Dr Silverstein, University of Michigan, Room 8301 MSRB3, Ann Arbor, MI 48109-0646.

E-mail: fsilvers@med.umich.edu or Dr. Jensen, Department of Neurology, Enders 348, Children's Hospital, 300 Longwood Avenue, Boston, MA 02115. E-mail: frances.jensen@childrens.harvard.edu 
cally generated seizures and whether they should be treated with anticonvulsants are unresolved questions.

In neonates, single seizures are unusual, and recurrence is expected without treatment. A specific cause can be identified much more commonly than in older children. The underlying cause of seizures is a significant determinant of neurological outcome, and this has resulted in some skepticism about the potential positive impact of effective anticonvulsant therapy on neurodevelopmental outcome.

\section{Diagnosis}

The electrographic features of neonatal seizures are also distinctive, and interpretation of neonatal EEG results is often particularly challenging. ${ }^{5}$ In view of the more subtle electrographic features of ictal events in neonates, a burst duration of $\geq 10$ seconds (vs 3 seconds in older age groups) is required to diagnose an electrographic seizure. There is no consensus about the definition of status epilepticus in neonates. One operational definition suggested, based on EEG criteria, is that more than $50 \%$ of the EEG analyzed demonstrates on-going seizures, ${ }^{7}$ and it is generally defined as 30 minutes of ongoing seizures. ${ }^{8}$

Investigators have incorporated video-EEG analysis to correlate behavioral events with electrographic seizures. Mizrahi and Kellaway ${ }^{9}$ found that focal clonic seizures, some forms of myoclonic seizures, and focal tonic seizures were most consistently associated with electrical seizure activity, whereas most "subtle" seizures, all generalized tonic seizures, and some forms of myoclonic seizures were either not associated with EEG seizure activity or had an inconsistent relationship with such activity. Seizures that were consistently and coherently related to focal EEG seizure activity had a high correlation with focal brain lesions and a favorable short-term outcome. Seizures with no relationship or an inconsistent relationship to EEG seizure activity were correlated with diffuse processes such as hypoxicischemic encephalopathy and a poor short-term outcome.

In view of this diagnostic complexity, some experts argue that the diagnosis of neonatal seizures cannot/ should not be based on clinical observation alone; however, in most neonatal intensive care units (ICUs), EEGs are not immediately available, and the initial diagnosis and treatment of seizures are currently based on clinical observation and assessment. In clinical practice, EEGs are often ordered after administration of antiepileptic drugs (AEDs). In contrast, with clinical practice in older age groups, a full loading dose of an AED (most commonly phenobarbital; see later) is administered quickly after a single seizure is diagnosed because of anticipated seizure recurrence. A relatively common trend in encephalopathic neonates with seizures is the persistence of electrographic seizures after initiation of
AED therapy. There is no agreement about optimal treatment in this setting. ${ }^{10}$

An important emerging change in clinical practice is the utilization of amplitude-integrated EEG devices in neonatal ICUs. These devices, which permit concurrent visualization of raw EEG tracings, were initially applied to assess cerebral functional integrity (amplitude, frequency); however, amplitude-integrated EEG patterns suggestive of seizures are recognized by experienced observers, and new algorithms (proprietary) for automated seizure detection are available. Whether this type of "brain monitoring," which could increase the recognition (and treatment) of subtle seizures, will improve neurodevelopmental outcome is unknown. Ongoing studies are comparing the accuracy and sensitivity of amplitude-integrated EEG or other limited montages and conventional EEG for seizure detection. ${ }^{11-13}$

\section{Causative Factors}

The neonatal period (the first 28 days of life) has the greatest incidence of seizures across the life span at 1.8 to 3.5 per 1,000 live births. ${ }^{14-16}$ The most common cause of neonatal seizures is hypoxic-ischemic encephalopathy, which occurs in approximately 1 to 2 per 1,000 live births. ${ }^{17-19}$ In the neonate, a broad range of systemic and central nervous system disorders can increase the risk for seizures (Table). Assessment of cause and initial treatment typically occur concurrently. The highest priority is identification of treatable systemic causes of seizures, including metabolic derangements (hypoglycemia, hypocalcemia, hypomagnesemia) and infection. The predominant cause is to some degree dependent on the setting. In a recently reported study from a tertiary care referral neonatal ICU, about twothirds were associated with hypoxic-ischemic encephalopathy or cerebrovascular disorders. ${ }^{20}$

Although the term infant is at high risk for seizures, it is increasingly recognized that seizures can be a significant problem in preterm infants. A recent populationbased cohort of very-low-birth-weight infants in Israel reported an overall incidence of neonatal seizures of $5.6 \%$. Younger gestational age, male sex, and major systemic (eg, sepsis) and neurological comorbidities (eg, intraventricular hemorrhage or periventricular leukomalacia) were all independent predictors of neonatal seizures. $^{21,22}$

Infants with neonatal encephalopathy as a result of hypoxia-ischemia are at particularly high risk for seizures. In two recent clinical trials of hypothermia for treatment of neonatal hypoxic-ischemic encephalopathy, seizures were frequent at the time of randomization $(40-60 \%){ }^{23,24}$ Cerebrovascular disorders including arterial and venous stroke, intracerebral hemorrhage, and subarachnoid hemorrhage also frequently present clinically with seizures. Thus, brain imaging is an essential component of the diagnostic evaluation, 
Table. Diverse Causes of Neonatal Seizures

\section{Acute metabolic \\ Hypoglycemia \\ Hypocalcemia \\ Hypomagnesemia \\ Hyponatremia or hypernatremia}

Withdrawal syndromes associated with maternal drug use

Iatrogenic associated with inadvertent fetal administration of local anesthetic

Rare inborn errors of metabolism (including pyridoxine responsive)

\section{Cerebrovascular}

Arterial and venous ischemic stroke

Intracerebral hemorrhage

Intraventricular hemorrhage

Subdural hemorrhage

Subarachnoid hemorrhage

Central nervous system infection

Bacterial meningitis

Viral meningoencephalitis

Intrauterine ("TORCH") infections

Developmental

Multiple forms of cerebral dysgenesis

Hypoxic-ischemic encephalopathy

Rare genetic syndromic disorders

Benign neonatal familial convulsions (sodium and potassium channel mutations identified)

Early myoclonic encephalopathy

This is not an exhaustive list, but rather is intended to illustrate the diversity of causative factors encountered in this population.

and magnetic resonance imaging is gaining acceptance as the optimal neuroimaging modality. Infants with complex congenital heart disease are at high risk for seizures in the perioperative period. ${ }^{25}$ Other less common causes of neonatal seizures include developmental abnormalities, inborn errors of metabolism, and other genetic syndromes that are cited in the Table and discussed in detail in reference texts. ${ }^{5,6}$

\section{Prognosis}

One of the first studies of the prognosis of neonatal seizures was a review of 277 newborns with seizures enrolled in the Collaborative Perinatal Project (data collected about 50 years ago). In this group, there was 35\% mortality, and $30 \%$ of survivors had adverse neurological outcomes at age 7 years, including cerebral palsy (13\%), intelligence quotient less than $70(19 \%)$, and epilepsy $(20 \%)$, alone or in combination. ${ }^{26}$ In a recent study of 89 term infants with clinical seizures, there was markedly less neonatal mortality (7\%), but a remarkably similar degree of poor long-term neurological outcome in $28 \% .^{20}$ Analysis of risk factors in the latter study demonstrated a strong association between seizure cause and outcome; cerebral dysgenesis and global hypoxiaischemia were associated with poor outcome. Normal neonatal/early infancy neurological examination and normal/mildly abnormal neonatal EEG were associated with a favorable outcome, particularly if neonatal neuroimaging was normal. Indeed, the burden of electrographic seizures correlates with poor outcome. ${ }^{27}$

Some of the therapeutic nihilism regarding a rationale for aggressive treatment of neonatal seizures stems from observations that the underlying cause is a major determinant both of medical "refractoriness" and of neurodevelopmental outcome. Yet, there is evidence to suggest that the deleterious effects of seizures may be most pronounced in the setting of underlying hypoxic-ischemic brain injury. An intriguing study of neonates with severe hypoxic-ischemic encephalopathy (which has not been replicated) reported better outcome at age 3 after neonatal treatment with phenobarbital $(40 \mathrm{mg} / \mathrm{kg}){ }^{28}$

Mechanisms that could account for seizure-induced amplification of ischemic injury include increases in brain temperature and metabolic demands, generation of mediators (such as reactive oxygen species) that contribute to tissue damage, and disruption of endogenous protection and repair mechanisms. Important data were provided by a study that used magnetic resonance spectroscopy to evaluate brain metabolism and integrity in neonates with asphyxia and seizures. ${ }^{29}$ This analysis demonstrated that seizures contributed to abnormal metabolism (as measured by the lactate/choline ratio) and tissue injury (as measured by the $N$-acetylaspartate/choline ratio). 


\section{Antiepileptic Drug Therapy}

Rigorous evaluation of the efficacy of AED therapy in neonates is difficult. In view of the challenges inherent in behavioral diagnosis, incorporation of continuous EEG monitoring represents the gold standard for studies of therapeutic efficacy.

There is consensus that currently used anticonvulsants are often ineffective for treatment of neonatal seizures. ${ }^{3}$ Painter and colleagues ${ }^{30}$ classic study reported that in term infants with EEG-confirmed seizures, loading doses of phenobarbital and phenytoin were equally but incompletely effective, and that either drug alone controlled seizures in fewer than half. Variable efficacy (ranging from minimal to $100 \%$ ) has been reported for midazolam as a second-line medication. ${ }^{31,32}$ Lidocaine is an effective treatment for refractory neonatal seizures, but concerns about cardiac toxicity have limited widespread adoption of this agent. ${ }^{33}$ An equally important question about AED therapy in neonates is whether chronic therapy is warranted after successful treatment of seizures. In encephalopathic infants, seizures often wane abruptly by the end of the first week of life; although it is unknown whether continuation of AED therapy is of benefit, this practice is quite common. ${ }^{1}$ Clinical studies of early-life anticonvulsant treatment on cognitive and neurological development are invariably confounded by the multiple underlying causes of neonatal seizures, and it will be essential to develop comprehensive strategies for delineation of relatively homogeneous clinical populations for such studies.

\section{Pathophysiology of Neonatal Seizures}

Developmental stage-specific mechanisms influence the generation of seizures, the impact of seizures on brain structure and function, intrinsic adaptive responses mechanisms, and the impact of anticonvulsant therapy. We highlight advances in three important areas: developmental regulation of factors governing neuronal excitability (neurotransmitters and receptors, ion homeostasis), studies in animal models of neonatal seizures, and developmental stage-specific effects of anticonvulsants. An important rationale for studies of these distinctive developmental mechanisms is that they should provide important clues for the age-specific therapy.

\section{Factors Governing Neuronal Excitability}

Multiple factors conspire to enhance synaptic excitation in the neonatal brain. Indeed, in humans, synapse and dendritic spine density are both peaking around birth and into the first months of life. ${ }^{34-36}$ Considerable experimental data implicate developmental changes in the major central nervous system excitatory class of glutamate neurotransmitter receptors and those of the major inhibitory class of $\gamma$-amino butyric acid (GABA) receptors as pivotal mechanisms that underlie the greater susceptibility of the immature brain to sei- zures. $^{37,38}$ There is abundant evidence from animal models and human tissue studies that neurotransmitter receptors are highly developmentally regulated (Fig).

Glutamate receptors are critical for plasticity and are transiently overexpressed during development compared with adulthood. A relative overexpression of certain glutamate receptor subtypes in both rodent and human developing cortex coincides with ages of increased seizure susceptibility (see Fig). ${ }^{37,39-41}$ Yet, the extent to which specific glutamate receptors contribute to increased susceptibility to seizures in neonates is currently unclear. Glutamate receptors include both ligand-gated ion channels, permeable to sodium, potassium, and in some cases calcium, and metabotropic subtypes. ${ }^{42,43}$ They are localized both to synapses and nonsynaptic sites on neurons, and are also expressed on glia. The ionotropic receptor subtypes are classified based on selective activation by specific ligands, $N$-methyl-D-aspartate (NMDA), $\alpha$-amino-3-hydroxy-5-methyl-4-isoxazolepropionic acid (AMPA), and kainate.

NMDA receptors are heteromeric, including an obligate NR1 subunit, and their makeup is developmentally regulated. In the immature brain, the predominant NR2 subunit is the NR2B subunit, which

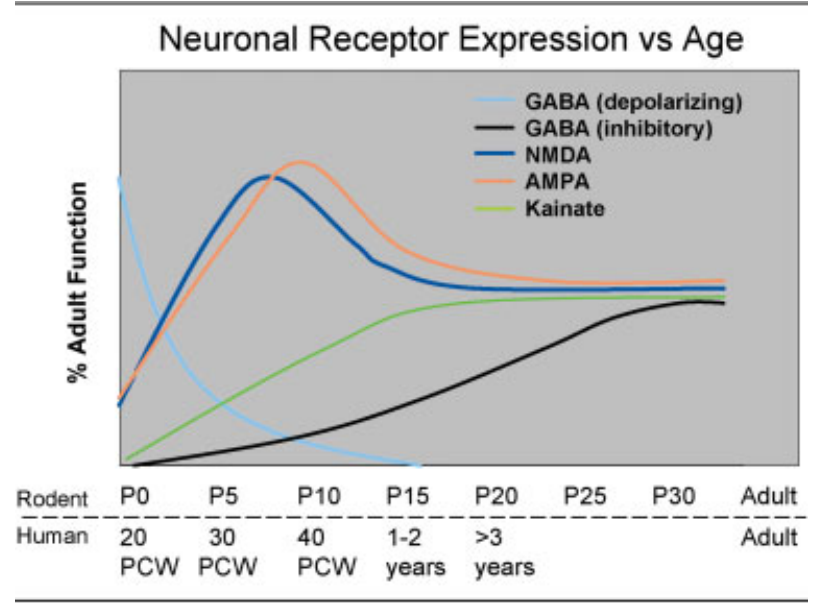

Fig. Schematic depiction of maturational changes in glutamate and GABA receptor expression and function in the developing brain. Developmental pattern for rat (top $\mathrm{x}$-axis) and human (bottom $\mathrm{x}$-axis) are shown, based on recent literature. 37,39,40,69 $G A B A$ receptors are depolarizing (light blue line) early in the first postnatal week in the rat and up to and including the neonatal period in the human, whereas functional inhibition (black line) is gradually reached over development. ${ }^{69}$ Before full maturation of GABA-mediated inhibition, the N-methyl$D$-aspartate (NMDA; dark blue line) and $\alpha$-amino-3hydroxy-5-methyl-4-isoxazolepropionic acid (AMPA; orange line) subtypes of glutamate receptors peak between the first and second postnatal weeks in the rat and in the neonatal period in the human. Kainate receptor binding (green line) is initially low and gradually increases to adult levels by the fourth postnatal week. ${ }^{94}$ 
functionally results in longer current decay time compared with the NR2A subunit, which is highly expressed on mature neurons. Other developmentally regulated subunits of functional relevance include the NR2C, NR2D, and NR3A subunits that are increased in the first two postnatal weeks (in rodent brain) and the presence of which results in reduced magnesium sensitivity, resulting in increased excitability. ${ }^{42,44} \mathrm{Al}$ though this receptor may represent an age-specific therapeutic target, pharmacological strategies based on NMDA antagonism may inevitably be limited by the central roles that NMDA receptor activation plays in learning, memory, and brain development. ${ }^{45,46}$ However, future clinically applicable NMDA antagonist strategies would ideally target more specific downstream pathways that differentiate pathological from physiological actions.

The AMPA subtype of glutamate receptor is thought to subserve most fast excitatory synaptic transmission, and in the adult, most AMPA receptors are not calcium permeable. AMPA receptors are heteromeric and made up of four subunits, including combinations of the GluR1, GluR2, GluR3, or GluR4 subunits. ${ }^{42}$ However, in the immature rodent and human brain, AMPA receptors are calcium permeable because they lack the GluR2 subunit. ${ }^{41,47}$ AMPA receptor subunits are also developmentally regulated, with GluR2 expressed only at low levels until the third postnatal week in rodents and later in the first year of life in the human cortex. ${ }^{39,40}$ Hence, both NMDA and AMPA receptors are expressed at levels and with subunit composition that enhances excitability of neuronal networks around term in the human and in the first two postnatal weeks in the rodent. Indeed, this age window around term is the period of greatest incidence of seizures across the life span in the human, ${ }^{48,49}$ and similarly, in the rodent, seizure susceptibility peaks in the second postnatal week in many models. ${ }^{37,50}$

\section{Studies in Animal Models of Neonatal Seizures}

The majority of recent in vivo animal studies of neonatal seizures have been performed in rodent models. Limitations shared by all models include both the challenges inherent in precise correlation of developmental stage between neonatal rodents and humans, and accurate modeling of clinical disorders such as hypoxicischemic encephalopathy.

In immature rodent models of hypoxia-induced seizures, seizures are relatively refractory to GABA receptor agonist therapy. ${ }^{37}$ However, the AMPA receptor antagonists such as NBQX and topiramate blocked the acute seizures and long-term sequelae in this model. ${ }^{51-53}$ In addition, topiramate in combination with hypothermia markedly attenuates neonatal hypoxicischemic injury in the neonatal rodent. ${ }^{54}$ These findings are of particular relevance in that hypoxic-ischemic encephalopathy is one of the most common causes of seizures in neonates. ${ }^{20,55}$ In addition to the clinical evidence cited earlier, there is also experimental evidence that seizures generated during hypoxia contribute to hypoxia-induced neuronal damage, ${ }^{56}$ and that prevention and adequate treatment of seizures delay the onset of anoxic depolarization, and thereby ameliorate the neurological outcome after brain hypoxia in the newborn. ${ }^{57}$ In a complementary model, Yager and colleagues ${ }^{58}$ found that kainate-induced seizures amplified hypoxic-ischemic brain injury in a neonatal rat model. Of particular interest and potential clinical relevance was the finding that prevention of seizure-induced hyperthermia was protective ${ }^{59}$; these findings suggested that seizure-induced increases in brain temperature could underlie their deleterious effects in this setting. In a sheep model of perinatal asphyxia, the neuroprotective efficacy of hypothermia was lost when treatment was initiated after the onset of seizures. ${ }^{60}$

Few studies have addressed the efficacy of NMDA receptor antagonists in models of infantile or early-life seizures. The NMDA receptor antagonists MK801 and memantine are neuroprotective in neonatal hypoxicischemic injury models. However, MK801 had no seizure-suppressing efficacy in the rat hypoxic seizure model, ${ }^{51}$ and pretreatment with MK801 surprisingly enhanced the seizure severity in early-life seizures induced by the chemoconvulsant kainate. ${ }^{61}$

Expression and function of the inhibitory $\mathrm{GABA}_{\mathrm{A}}$ receptors are also developmentally regulated. Rodent studies show that GABA receptor binding, synthetic enzymes, and overall receptor expression are lower in early life compared with later. ${ }^{37,62}$ GABA receptor function is regulated by subunit composition, and the $\alpha 4$ and $\alpha 2$ subunits are relatively overexpressed in the immature brain compared with the $\alpha 1$ subunit. ${ }^{63}$ Notably, when the $\alpha 4$ subunit is expressed, the receptor is less sensitive to benzodiazepines compared with receptors containing $\alpha 1,{ }^{64}$ and as is often the case clinically, seizures in the immature rat respond poorly to benzodiazepines. ${ }^{51,65}$

Receptor expression and subunit composition can partially explain the resistance of seizures in the immature brain to conventional AEDs that act as GABA agonists. However, inhibition of neuronal excitability via GABA agonists relies on the ability of $G_{A B A}$ receptors to cause a net influx of chloride $\left(\mathrm{Cl}^{-}\right)$from the neuron, resulting in hyperpolarization. ${ }^{57}$ In immature forebrain, GABA receptor activation can cause depolarization rather than hyperpolarization. ${ }^{66-68} \mathrm{GABA}_{\mathrm{A}^{-}}$ mediated depolarization occurs because the $\mathrm{Cl}^{-}$gradient is reversed in the immature brain: $\mathrm{Cl}^{-}$levels are high in the immature brain because of a relative underexpression of the $\mathrm{Cl}^{-}$exporter $\mathrm{KCC} 2$ compared with mature brain (see Fig). ${ }^{69}$ Recent studies in human brain have shown that KCC2 is virtually absent in cor- 
tical neurons until late in the first year of life, and gradually increases thereafter, whereas the $\mathrm{Cl}^{-}$importer NKCC1 is overexpressed both in the neonatal human brain and during early life in the rat when seizures are resistant to $\mathrm{GABA}_{\mathrm{A}}$ agonists. ${ }^{69}$ The NKCC1 inhibitor, bumetanide, shows efficacy against kainateinduced seizures in the immature brain, suggesting that this agent, already Food and Drug Administration approved as a diuretic, may be clinically useful in treatment of neonatal seizures.

In addition to those noted earlier, multiple animal models of neonatal and early-life seizures show a similar resistance to conventional AEDs. These include seizures induced by systemically administered convulsants, such as kainate, pentylentrazol, flurothyl, and pilocarpine, and those administered intracerebrally, including tetanus toxin and kainate. ${ }^{70}$ It is widely observed that prolonged seizures and status in the immature rodent cause only minimal neuronal injury, in contrast with often extensive hippocampal and limbic injury in the adult rodent brain. ${ }^{71,72}$

In the past, this relative lack of detectable neuronal injury was interpreted as evidence that the immature brain was resistant to harmful effects of seizures. Yet, early studies in neonatal rats showed that flurothylinduced seizures resulted in reduced brain growth and DNA synthesis. ${ }^{73}$ More recent experimental data demonstrate significant long-term adverse consequences of seizures and status epilepticus in the immature brain. These include increases in seizure susceptibility in later life, ${ }^{74-77}$ as well as permanent impairments in learning, memory, and cognition. ${ }^{78,79}$ These adverse outcomes are not related to seizure-induced neuronal death but are attributable to altered neuronal connectivity ${ }^{80}$ and receptor expression. ${ }^{41,81,82}$ These studies suggest that the impact of seizure on the developing brain is qualitatively different from that in the adult.

The immature brain is an ideal substrate in which to study epileptogenesis and the effect of seizures on synaptic and network function during the developmental period when synaptogenesis and neuronal network expansion are robust. ${ }^{37,83}$ Many models demonstrate that neonatal seizures alter synaptic plasticity ${ }^{70}$ and recent studies are delineating the molecular signaling cascades that are altered after early-life seizures. ${ }^{82,84}$ Such information may identify seizure-induced therapeutic targets that will lead to strategies for disease modification, rather than simply anticonvulsant control.

\section{Anticonvulsants and the Developing Brain}

Emerging identification of age-specific mechanisms for neonatal seizures is pointing to the use of novel therapeutic targets. Caution must be exercised when devising new therapies because the target may indeed be essential for normal brain development, albeit a contributor to neuronal hyperexcitability.
More than two decades ago, experimental data emerged demonstrating that phenobarbital exposure had adverse effects on survival and morphology of cultured neurons, derived from fetal mouse tissue, and these observations raised concerns about risks of this drug for treatment of neonatal seizures. ${ }^{85,86}$ Subsequent studies in neonatal rats demonstrated that daily treatment with phenobarbital or diazepam in the first postnatal month resulted in measurable changes in regional cerebral metabolism and behavior. ${ }^{87,88}$

More recently, evidence emerged that brief systemic treatment with conventional AEDs such as phenobarbital, diazepam, phenytoin, and valproate all increase apoptotic neuronal death in normal immature rodents. ${ }^{89}$ Similarly, NMDA receptor antagonists also induce an increase in constitutive apoptosis in the developing rodent brain. ${ }^{90}$ Yet, the AMPA receptor antagonists $\mathrm{NBQX}$ and topiramate do not cause such adverse effects, ${ }^{90,91}$ although the mechanism for this relative safety over the other agents is not understood. The novel AED levetiracetam also has no effect on apoptosis in the developing brain. ${ }^{92}$

Despite these data on adverse effects or lack thereof in rodents, no evidence of similar phenomena exists for other species, and it remains unknown whether these toxicity mechanisms are relevant for human neonates. Moreover, interpretation of AED toxicity studies must be tempered by the consideration that these experiments are typically performed in normal animals, and that the impact of AED administration may well differ in normal animals and in those with seizures.

\section{Future Directions}

Refractory neonatal seizures remain a significant clinical problem, and no new treatments for this condition have been introduced for decades. There will certainly be opportunities to perform therapeutic trials of new agents with well-defined clinical outcome measures. Systematic clinical evaluation of safety and pharmacokinetics in the appropriate study populations must precede analysis of efficacy, and this is particularly challenging in neonates. Interdisciplinary collaboration between neonatologists and neonatal neurologists is essential for the success of such studies.

As basic research demonstrates new age-specific therapeutic targets, these targets can be validated with analysis of cell-specific gene and protein expression in human autopsy samples. Although the experimental data regarding the potential efficacy of agents such as bumetanide, topiramate, and levetiracetam are encouraging, the duration of use of these agents may be limited by safety concerns related to their effects on long-term brain development. Animal model trials and human studies must be aligned to understand how safety and efficacy data from rodent and nonhuman primates predict human responses. A number of early-life seizure 
models exist in which there are indeed long-term effects on learning, and these could also be used to address the effects of treatment on brain and cognitive development.

Clinical research is evolving to include new methods for seizure detection in the newborn. There is no widely approved consensus regarding optimal "standard" lead montage for EEG monitoring such as that which exists for older children and adults, ${ }^{11,12}$ and unique logistical factors suggest that fewer leads may be more clinically appropriate. There is considerable enthusiasm for introduction of amplitude-integrated EEG devices into neonatal ICUs, although their sensitivity and specificity for seizure detection remain uncertain. ${ }^{11,93}$ Clinical therapeutic trials in neonates would be greatly improved if there were accurate biomarkers of acute and chronic therapeutic efficacy, yet none exists other than the EEG. Measures of brain metabolic integrity such as magnetic resonance spectroscopy or near-infrared spectroscopy, when combined with EEG data, may provide surrogate measures of treatment efficacy.

Although it is clear that there are emerging technologies and therapeutic strategies available for study in neonatal seizures, there are many practical challenges that must be addressed to implement clinical trials of new AEDs in neonates. Incorporation of continuous EEG monitoring into clinical studies of neonatal seizure therapy is a daunting task. Delineation of reasonably homogeneous clinical populations for study and/or practical stratification strategies that take into account the critical factors that contribute to outcome, including gestational age, seizure cause, and systemic disorders, and their treatments are essential prerequisites for trials of anticonvulsant efficacy, as well as neurological outcomes. It will also be essential to assess AED interactions with other therapies (eg, induced hypothermia) in critically ill infants.

Recent surveys of neurologists and neonatologists (F.S.S., unpublished data) suggest that the majority of physicians who treat neonatal seizures do not think that a study designed with a placebo-treated or delayed-treatment control group is ethically justifiable or feasible currently. A substantial majority support a study design with randomization for an add-on drug study (with varying entry criteria). Seizure cessation is an important therapeutic goal; yet, improved neurodevelopmental outcome is clearly of critical importance.

This work was supported by the NIH (NS35059, F.S.S.; NS31718, F.E.J.), and sabbatical support was given by the Departments of Pediatrics and Neurology, University of Michigan (F.S.S.).

\section{References}

1. Bartha A, Shen J, Katz KH. Neonatal seizures: multi-center variability in current treatment practices. J. Child Neurol. (in press).

2. Booth D, Evans DJ. Anticonvulsants for neonates with seizures. Cochrane Database Syst Rev 2004;CD004218.

3. Sankar R, Painter MJ. Neonatal seizures: after all these years we still love what doesn't work. Neurology 2005;64:776-777.

4. Boylan GB, Rennie JM. Automated neonatal seizure detection. Clin Neurophysiol 2006;117:1412-1413.

5. Mizrahi EM, Kellaway P. Diagnosis and management of neonatal seizures. Philadelphia: Lippincott-Raven, 1998.

6. Volpe JJ. Neonatal seizures. In: Neurology of the newborn. 4th ed. Philadelphia: WB Saunders, 2001:178-214.

7. Scher MS, Alvin J, Gaus L, et al. Uncoupling of EEG-clinical neonatal seizures after antiepileptic drug use. Pediatr Neurol 2003;28:277-280.

8. Lowenstein DH. Status epilepticus: an overview of the clinical problem. Epilepsia 1999;40(suppl 1):S3-S8.

9. Mizrahi EM, Kellaway P. Characterization and classification of neonatal seizures. Neurology 1987;37:1837-1844.

10. Boylan GB, Rennie JM, Pressler RM. Phenobarbitone, neonatal seizures, and video-EEG. Arch Dis Child Fetal Neonatal Ed 2002;86:F165-F170.

11. Tekgul H, Bourgeois BF, Gauvreau K, et al. Electroencephalography in neonatal seizures: comparison of a reduced and a full 10/20 montage. Pediatr Neurol 2005;32:155-161.

12. Clancy RR. The contribution of EEG to the understanding of neonatal seizures. Epilepsia 1996;37(suppl 1):S52-S59.

13. Clancy RR. Summary proceedings from the neurology group on neonatal seizures. Pediatrics 2006;117:S23-S27.

14. Cowan LD. The epidemiology of the epilepsies in children. Ment Retard Dev Disabil Res Rev 2002;8:171-181.

15. Cowan F, Rutherford M, Groenendaal F, et al. Origin and timing of brain lesions in term infants with neonatal encephalopathy. Lancet 2003;361:736-742.

16. Hauser WA, Kurland LT. The epidemiology of epilepsy in Rochester, Minnesota, 1935 through 1967. Epilepsia 1975;16: $1-66$.

17. Ronen GM, Penney S, Andrews W. The epidemiology of clinical neonatal seizures in Newfoundland: a population-based study. J Pediatr 1999;134:71-75.

18. Lanska MJ, Lanska DJ, Baumann RJ, et al. A population-based study of neonatal seizures in Fayette County, Kentucky. Neurology 1995; 45:724-732.

19. Saliba RM, Annegers JF, Waller DK, et al. Incidence of neonatal seizures in Harris County, Texas, 1992-1994. Am J Epidemiol 1999;150:763-769.

20. Tekgul H, Gauvreau K, Soul J, et al. The current etiologic profile and neurodevelopmental outcome of seizures in term newborn infants. Pediatrics 2006;117:1270-1280.

21. Kohelet D, Shochat R, Lusky A, et al. Risk factors for neonatal seizures in very low birthweight infants: population-based survey. J Child Neurol 2004;19:123-128.

22. Kohelet D, Shochat R, Lusky A, et al. Risk factors for seizures in very low birthweight infants with periventricular leukomalacia. J Child Neurol 2006;21:965-970.

23. Shankaran S, Laptook AR, Ehrenkranz RA, et al. Whole-body hypothermia for neonates with hypoxic-ischemic encephalopathy. N Engl J Med 2005;353:1574-1584.

24. Gluckman PD, Wyatt JS, Azzopardi D, et al. Selective head cooling with mild systemic hypothermia after neonatal encephalopathy: multicentre randomised trial. Lancet 2005; 365:663-670.

25. Clancy RR, Sharif U, Ichord R, et al. Electrographic neonatal seizures after infant heart surgery. Epilepsia 2005;46:84-90. 
26. Holden KR, Mellits ED, Freeman JM. Neonatal seizures. I. Correlation of prenatal and perinatal events with outcomes. Pediatrics 1982;70:165-176.

27. McBride MC, Laroia N, Guillet R. Electrographic seizures in neonates correlate with poor neurodevelopmental outcome. Neurology 2000;55:506-513.

28. Hall RT, Hall FK, Daily DK. High-dose phenobarbital therapy in term newborn infants with severe perinatal asphyxia: a randomized, prospective study with three-year follow-up. J Pediatr 1998; 132:345-348.

29. Miller SP, Weiss J, Barnwell A, et al. Seizure-associated brain injury in term newborns with perinatal asphyxia. Neurology 2002;58:542-548.

30. Painter MJ, Scher MS, Stein AD, et al. Phenobarbital compared with phenytoin for the treatment of neonatal seizures. N Engl J Med 1999;341:485-489.

31. Boylan GB, Young K, Panerai RB, et al. Dynamic cerebral autoregulation in sick newborn infants. Pediatr Res 2000;48: $12-17$.

32. Carmo KB, Barr P. Drug treatment of neonatal seizures by neonatologists and paediatric neurologists. J Paediatr Child Health 2005;41:313-316.

33. Malingre MM, Van Rooij LG, Rademaker CM, et al. Development of an optimal lidocaine infusion strategy for neonatal seizures. Eur J Pediatr 2006;165:598-604.

34. Takashima S, Chan F, Becker LE, et al. Morphology of the developing visual cortex of the human infant: a quantitative and qualitative Golgi study. J Neuropathol Exp Neurol 1980;39: 487-501.

35. Rakic P, Bourgeois JP, Eckenhoff MF, et al. Concurrent overproduction of synapses in diverse regions of primate cortex. Science 1989;232:232-235.

36. Huttenlocher PR, deCourten C, Garey LJ, et al. Synaptogenesis in human visual cortex-evidence for synapse elimination during normal development. Neurosci Lett 1982;33:247.

37. Sanchez RM, Jensen FE. Maturational aspects of epilepsy mechanisms and consequences for the immature brain. Epilepsia 2001;42:577-585.

38. Johnston MV. Neurotransmitters and vulnerability of the developing brain. Brain Dev 1995;17:301-306.

39. Talos DM, Fishman RE, Park H, et al. Developmental regulation of alpha-amino-3-hydroxy-5-methyl-4-isoxazole-propionic acid receptor subunit expression in forebrain and relationship to regional susceptibility to hypoxic/ischemic injury. I. Rodent cerebral white matter and cortex. J Comp Neurol 2006;497: 42-60.

40. Talos DM, Follett PL, Folkerth RD, et al. Developmental regulation of alpha-amino-3-hydroxy-5-methyl-4-isoxazole-propionic acid receptor subunit expression in forebrain and relationship to regional susceptibility to hypoxic/ischemic injury. II. Human cerebral white matter and cortex. J Comp Neurol 2006;497:61-77.

41. Sanchez RM, Koh S, Rio C, et al. Decreased glutamate receptor 2 expression and enhanced epileptogenesis in immature rat hippocampus after perinatal hypoxia-induced seizures. J Neurosci 2001;21:8154-8163.

42. Hollmann M, Heinemann S. Cloned glutamate receptors. Annu Rev Neurosci 1994;17:31-108.

43. Choi DW. Glutamate receptors and the induction of excitotoxic neuronal death. Prog Brain Res 1994;100:47-51.

44. Wong HK, Liu XB, Matos MF, et al. Temporal and regional expression of NMDA receptor subunit NR3A in the mammalian brain. J Comp Neurol 2002;450:303-317.

45. Jensen FE. Developmental factors regulating susceptibility to perinatal brain injury and seizures. Curr Opin Pediatr 2006;18: $628-633$.

46. Johnston MV. Excitotoxicity in perinatal brain injury. Brain Pathol 2005;15:234-240.
47. Kumar SS, Bacci A, Kharazia V, et al. A developmental switch of AMPA receptor subunits in neocortical pyramidal neurons. J Neurosci 2002;22:3005-3015.

48. Hauser WA, Annegers JF, Kurland LT. Incidence of epilepsy and unprovoked seizures in Rochester, Minnesota: 1935-1984. Epilepsia 1993;34:453-468.

49. Aicardi J, Chevrie JJ. Convulsive status epilepticus in infants and children. A study of 239 cases. Epilepsia 1970;11:187-197.

50. Sanchez RM, Jensen FE. Modeling hypoxia-induced seizures and hypoxic encephalopathy in the neonatal period. In: Pitanken A, Schwartzkroin PA, Moshe SL, eds. Models of seizures and epilepsy. San Diego: Elsevier Press, 2005.

51. Jensen FE, Alvarado S, Firkusny IR, et al. NBQX blocks the acute and late epileptogenic effects of perinatal hypoxia. Epilepsia 1995;36:966-972.

52. Koh S, Jensen FE. Topiramate blocks perinatal hypoxiainduced seizures in rat pups. Ann Neurol 2001;50:366-372.

53. Koh S, Tibayan FD, Simpson J, et al. NBQX or topiramate treatment following perinatal hypoxia-induced seizures prevents later increases in seizure-induced neuronal injury. Epilepsia 2004; 45:569-575.

54. Liu Y, Barks JD, Xu G, et al. Topiramate extends the therapeutic window for hypothermia-mediated neuroprotection after stroke in neonatal rats. Stroke 2004;35:1460-1465.

55. Volpe JJ. Hypoxic-Ischemic Encephalopathy: Biochemical and Physiological Aspects. In: Neurology of the newborn. 4th ed. Philadelphia: WB Saunders, 2000:217-276.

56. Williams PA, Dou P, Dudek FE. Epilepsy and synaptic reorganization in a perinatal rat model of hypoxia-ischemia. Epilepsia 2004; 45:1210-1218.

57. Dzhala VI, Staley KJ. Excitatory actions of endogenously released GABA contribute to initiation of ictal epileptiform activity in the developing hippocampus. J Neurosci 2003;23: $1840-1846$.

58. Yager JY, Armstrong EA, Miyashita H, et al. Prolonged neonatal seizures exacerbate hypoxic-ischemic brain damage: correlation with cerebral energy metabolism and excitatory amino acid release. Dev Neurosci 2002;24:367-381.

59. Yager JY, Armstrong EA, Jaharus C, et al. Preventing hyperthermia decreases brain damage following neonatal hypoxicischemic seizures. Brain Res 2004;1011:48-57.

60. Gunn AJ, Bennet L, Gunning MI, et al. Cerebral hypothermia is not neuroprotective when started after postischemic seizures in fetal sheep. Pediatr Res 1999;46:274-280.

61. Stafstrom CE, Tandon P, Hori A, et al. Acute effects of MK801 on kainic acid-induced seizures in neonatal rats. Epilepsy Res 1997;26:335-344.

62. Swann JW, Brady RJ, Martin DL. Postnatal development of GABA-mediated synaptic inhibition in rat hippocampus. Neuroscience 1989;28:551-561.

63. Brooks-Kayal A, Jin H, Price M, et al. Developmental expression of GABA(A) receptor subunit mRNAs in individual hippocampal neurons in vitro and in vivo. J Neurochem 1998;70: 1017-1028.

64. Kapur J, Macdonald RL. Postnatal development of hippocampal dentate granule cell g-aminobutyric acid $_{\mathrm{A}}$ receptor pharmacological properties. Mol Pharmacol 1999;55:444-452.

65. Swann J, Moshe SL. Developmental issues in animal models. In: Engel J Jr, Pedley TA, eds. Epilepsy: a comprehensive textbook. Philadelphia: Lippincott-Raven Publishers, 1997: 467-480

66. Khazipov R, Khalilov I, Tyzio R, et al. Developmental changes in GABAergic actions and seizure susceptibility in the rat hippocampus. Eur J Neurosci 2004;19:590-600.

67. Loturco JJ, Owens DF, Heath MJ, et al. GABA and glutamate depolarize cortical progenitor cells and inhibit DNA synthesis. Neuron 1995;15:1287-1298. 
68. Owens DF, Boyce LH, Davis MB, et al. Excitatory GABA responses in embryonic and neonatal cortical slices demonstrated by gramicidin perforated-patch recordings and calcium imaging. J Neurosci 1996;16:6414-6423.

69. Dzhala VI, Talos DM, Sdrulla DA, et al. NKCC1 transporter facilitates seizures in the developing brain. Nat Med 2005;11: $1205-1213$.

70. Stafstrom CE, Moshe SL, Swann JW, et al. Models of pediatric epilepsies: strategies and opportunities. Epilepsia 2006;47: $1407-1414$.

71. Haas KZ, Sperber EF, Opanashuk LA, et al. Resistance of immature hippocampus to morphologic and physiologic alterations following status epilepticus or kindling. Hippocampus 2001;11:615-625.

72. Wasterlain CG, Niquet J, Thompson KW, et al. Seizureinduced neuronal death in the immature brain. Prog Brain Res 2002;135:335-353.

73. Wasterlain CG. Neonatal seizures and brain growth. Neuropadiatrie 1978;9:213-228

74. Huang L, Cilio MR, Silveira DC, et al. Long-term effects of neonatal seizures: a behavioral, electrophysiological, and histological study. Brain Res Dev Brain Res 1999;118:99-107.

75. Jensen FE, Holmes GL, Lombroso CT, et al. Age dependent changes in long term seizure susceptibility and behavior after hypoxia in rats. Epilepsia 1992;33:971-980.

76. Lee CL, Hannay J, Hrachovy R, et al. Spatial learning deficits without hippocampal neuronal loss in a model of early-onset epilepsy. Neuroscience 2001;107:71-84.

77. Swann JW. Recent experimental studies of the effects of seizures on brain development. Prog Brain Res 2002;135: 391-393.

78. Sayin U, Sutula TP, Stafstrom CE. Seizures in the developing brain cause adverse long-term effects on spatial learning and anxiety. Epilepsia 2004;45:1539-1548.

79. Cornejo BJ, Mesches MH, Coultrap S, et al. A single episode of neonatal seizures permanently alters glutamatergic synapses. Ann Neurol 2007;61:411-426.

80. Swann JW, Hablitz JJ. Cellular abnormalities and synaptic plasticity in seizure disorders of the immature nervous system. Ment Retard Dev Disabil Res Rev 2000;6:258-267.

81. Brooks-Kayal AR. Rearranging receptors. Epilepsia 2005; 46(suppl 7):29-38.
82. Sanchez RM, Dai W, Levada RE, et al. AMPA/kainate receptor-mediated downregulation of GABAergic synaptic transmission by calcineurin after seizures in the developing rat brain. J Neurosci 2005;25:3442-3451.

83. Jensen FE. The role of glutamate receptor maturation in perinatal seizures and brain injury. Int J Dev Neurosci 2002;20: $339-347$

84. Raol YH, Lund IV, Bandyopadhyay S, et al. Enhancing GABA(A) receptor alpha 1 subunit levels in hippocampal dentate gyrus inhibits epilepsy development in an animal model of temporal lobe epilepsy. J Neurosci 2006;26:11342-11346.

85. Bergey GK, Swaiman KF, Schrier BK, et al. Adverse effects of phenobarbital on morphological and biochemical development of fetal mouse spinal cord neurons in culture. Ann Neurol 1981;9:584-589.

86. Serrano EE, Kunis DM, Ransom BR. Effects of chronic phenobarbital exposure on cultured mouse spinal cord neurons. Ann Neurol 1988;24:429-438.

87. Pereira de Vasconcelos A, Colin C, Desor D, et al. Influence of early neonatal phenobarbital exposure on cerebral energy metabolism and behavior. Exp Neurol 1990;108:176-187.

88. Schroeder H, Humbert AC, Koziel V, et al. Behavioral and metabolic consequences of neonatal exposure to diazepam in rat pups. Exp Neurol 1995;131:53-63.

89. Bittigau P, Sifringer M, Genz K, et al. Antiepileptic drugs and apoptotic neurodegeneration in the developing brain. Proc Natl Acad Sci U S A 2002;99:15089-15094.

90. Ikonomidou C, Bosch F, Miksa M, et al. Blockade of NMDA receptors and apoptotic neurodegeneration in the developing brain. Science 1999;283:70-74.

91. Glier C, Dzietko M, Bittigau P, et al. Therapeutic doses of topiramate are not toxic to the developing rat brain. Exp Neurol 2004;187:403-409.

92. Manthey D, Asimiadou S, Steforska V, et al. Sulthiame but not levetiracetam exerts neurotoxic effect in the developing rat brain. Exp Neurol 2005;193:497-503.

93. de Vries LS, Toet MC. Amplitude integrated electroencephalography in the full-term newborn. Clin Perinatol 2006;33: 619-632, vi.

94. Kidd FL, Isaac JT. Developmental and activity-dependent regulation of kainate receptors at thalamocortical synapses. Nature 1999; 400:569-573. 